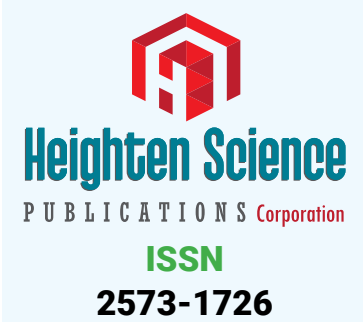

*Address for Correspondence: Javier Calderón Montero, Physical and Sports Education, Research Group of the Physiology of Effort Laboratory, Spain Tel: 512-400-0398 (or) 91-33640-20; Email: franciscojavier.calderon@upm.es

Submitted: 14 December 2018

Approved: 31 January 2019

Published: 01 February 2019

Copyright: (c) 2019 Montero JC. This is an open access article distributed under the Creative Commons Attribution License, which permits unrestricted use, distribution, and reproduction in any medium, provided the original work is properly cited

Check for updates
Review Article

\section{Renal function during exercise and recovery}

\author{
Javier Calderón Montero* \\ Physical and Sports Education, Research Group of the Physiology of Effort Laboratory, Spain
}

\section{Abstract}

This review paper analyzes the response of renal function during two types of exercise: 1) exercise of increasing intensity and 2) exercise of submaximal intensity and prolonged duration. During an effort of increasing intensity there is a decrease in renal blood flow that, theoretically, could compromise renal function. However, several studies seem to show that the kidney has self-regulatory mechanisms that allow maintaining the filtration fraction. On the other hand, ultra resistance exercises, such as ironman, are becoming more frequent. Knowing the renal response to this type of exercise is essential to apply knowledge to emergency situations such as dehydration or hyponatremia.

\section{Introduction}

The function of the kidneys in vertebrates is not limited to the plasma filtration process. Since the final result of renal function, urine, is practically water, electrolytes and waste substances, implies that the kidney plays a major role in the regulation of body fluids. The kidney intervenes with great precision on the extracellular fluid both quantitatively and qualitatively. For this you have two possibilities. First, the kidney is able to concentrate or dilute urine through complex mechanisms. Secondly, the kidney is the "target organ" of hormonal systems that play a decisive role in the formation of a concentrated or diluted urine.

Apart from this transcendental function in the control of hydroelectrolytic homeostasis, this double organ intervenes in the following general functions:

1. control of acid-base balance

2. the control of erythropoiesis, since it is the main organ in secreting erythropoietin, a hormone that stimulates the bone marrow

3. the control of calcium homeostasis, since it transforms 25 hydroxycholecalciferol, that is, into physiologically active vitamin D.

Thus, the magnitude of renal function transcends that corresponding to the formation of urine. However, in this revision work the indicated functions will not be addressed. Despite the importance of the renal function reviewed, it is paradoxical that the treatment given in the exercise physiology books. For example, in two books widely used in the field of exercise physiology $[1,2]$ there are no specific sections related to renal function during exercise. What may be the reasons why this part of physiology has not been addressed, even in an elementary way, in the physiology texts of the exercise of frequent use? The reasons may be the following:

1. The kidney is a "silent" organ during physical exercise that does not intervene in the supply of oxygen and obtaining energy. This may determine that it is not necessary to study kidney function during exercise. 
2. The complexity of the study of renal function during exercise, which is limited to the analysis of urine and inferring renal function.

However, these reasons are somewhat weak, since this body is primarily responsible for the quantitative and qualitative control of the extracellular fluid. The study of renal function during physical exercise and prolonged duration is essential to understand the participation of the kidney in the regulation of body fluids and the recovery process after training. Despite the aforementioned, some researchers have shown interest in the kidney-exercise relationship. Mainly, the interest in renal function during exercise can be grouped into two types of questions that, as often happens, allude to physiology and pathology and that are listed in the form of the following questions:

1모 ) Does the reduction of FSR affect renal function during exercise? [3-6].

2) How does it participate in the kidney during efforts in which the loss of fluid is considerable? [7-11].

$3^{\mathrm{a}}$ ) What is the origin of some of the renal alterations that athletes suffer? Are these alterations transitory or can they harm the athlete's health in the long term, once he has left the competition? [3-6].

This review paper analyzes in a simple way the renal function in exercise and postexercise situation based on the research carried out, fundamentally in two types of efforts:

\section{Exercise of increasing intensity and short duration}

The release of this acid can compromise the acid-base state. The importance of renal function lies in reversing the state of metabolic acidosis. This is not a simple process and requires time after the end of the exercise. Unfortunately, there are few articles that address the role of the kidney during recovery. An elementary search in medline (renal function AND post-exercise AND recovery in title / abstract) shows 3 articles, two of which $[12,13]$ study renal function in resistance efforts

In a simple way, table 1 shows the situation of imbalance that has occurred as a result of a high intensity exercise during a limited period of time. The analysis of the table allows us to ask the following questions:

$1^{a}$ ) given the need to restore the acid base state to the resting situation, to what extent does renal function intervene? The situation of metabolic acidosis triggered by the release of acids into the bloodstream during intense exercise must be compensated in an elementary manner with the replacement of the "spent base" as a result of the plasma buffer.

$2^{\text {nd }}$ ) inevitably, the restitution of spent bicarbonate determines the elimination of acids by urine. This elimination is done in a controlled manner by the kidney, mainly through the elimination of an acid, the ammonium ion ( $\mathrm{NH}_{4}+$ ).

2) Renal function during an exercise of submaximal intensity and prolonged duration.

Unlike the efforts of high intensity and short duration, in the efforts of resistance or ultra-resistance, the renal function aims to maintain the hydro-electrolytic balance, since there is loss of water and electrolytes by the main mechanism of heat removal, sweating. Table 2 shows the fluid losses during the exercise of high intensity and prolonged duration. The analysis of the data in this table suggests two relevant considerations:

1a) Reduction of urine volume (oliguria). Logically, it is an "intelligent" adaptation of the organism, because it preserves it from a loss of fluid that would lead to dehydration in a short time, due to loss of water and electrolytes due to sweating. Now, how is oliguria related to renal function? 


\begin{tabular}{|c|c|c|c|c|c|}
\hline \multicolumn{7}{|c|}{ Table 1: Some parameters of the acid-base state after intense exercise. } \\
\hline & Reposo & $\mathbf{2 5} \%$ & $\mathbf{5 0} \%$ & $\mathbf{7 5} \%$ & $\mathbf{1 0 0} \%$ \\
\hline PH & 7,42 & 7,40 & 7,35 & 7,30 & 7,00 \\
\hline Exceso de bases (mEq/L) & 0 & & & & 193,3 \\
\hline Bicarbonato (mEq/L) & 24 & 24 & 24 & 22 & 18 \\
\hline
\end{tabular}

Table 2: Approximate loss of fluid at rest and exercise

\begin{tabular}{|c|c|c|}
\hline & REPOSO & EJERCICIO \\
\hline Riñón & $1400 \mathrm{ml}$ & $500 \mathrm{ml}$ \\
\hline Piel (transpiración) & $350 \mathrm{ml}$ & $350 \mathrm{ml}$ \\
\hline Pulmón & $350 \mathrm{ml}$ & $650 \mathrm{ml}$ \\
\hline Heces & $200 \mathrm{ml}$ & $200 \mathrm{ml}$ \\
\hline Piel (sudoración) & $100 \mathrm{ml}$ & $4000 \mathrm{ml}$ \\
\hline
\end{tabular}

$\left.2^{\text {nd }}\right)$ the loss of fluid requires the immediate restitution of the quantitative and qualitative levels of the two corporal compartments, in order to return to homeostasis: what type of water and electrolyte replacement should be done?

Next, renal function is approached in these two forms of exercise in a simple way based on the understanding of the functional unit of the kidney: the nephron. Of the general, in the different studies that have approached the renal function during the exercise there are two ways: 1st) according to the different parts of the nephron, you can study the glomerular and tubular functions in relation to the exercise and 2nd) depending on the functions of renal function (filtration, reabsorption, excretion and elimination).

\section{The renal function during the rising intensity exercise}

In regulated efforts such as those carried out during conventional stress tests or in those performed at intervals and intensities above the value corresponding to the maximum oxygen consumption, the anaerobic energy yield increases, with the consequent production of a strong acid ( $\mathrm{pK}=3.86$, [14]). The acid-base state during the exercise has been deeply studied from an elementary level to relatively deep physicalchemical explanations, so this section will be limited to explain the variations of the acid-base state from the renal perspective.

Lactic acid concentration / intensity ratio: It is amply demonstrated that the concentration of lactic acid in plasma increases as the intensity increases, experiencing an exponential increase from a certain load. Up to this value, known as the lactic threshold, the muscle is an excellent "buffer" of the acid load following the dissolution of the acid in water ( $\mathrm{LH}+\mathrm{H} 2 \mathrm{O}=\mathrm{L}-+\mathrm{H} 3 \mathrm{O}+$ ), since it has a high difference of strong ions (SID).) and a high concentration of anions (A-) [15]. However, when the production of lactic acid could exceed the capacity "cushioning" of the muscle, through a complex mechanism linked to transporters of monocarboxylic acids (MCT) [16], the "elimination" of the acid to the blood. Again, the cushioning capacity of this "liquid" fabric is remarkable. On the one hand, the erythrocytes have a high buffer capacity (high SID) and the fundamental function of hemoglobin. In addition, the high concentration of bases, mainly of sodium bicarbonate $(\mathrm{LH}+\mathrm{NaHCO} 3=\mathrm{LNa}+\mathrm{H} 2 \mathrm{CO} 3)$, make the plasma an extraordinary buffer solution: 1) it transforms a strong acid into its corresponding salt and $2^{\circ}$ ) a weak acid is formed, which can be "managed" through an open system, the respiratory system.

However, from the lactic threshold the buffer capacity of the plasma is overcome by the production and elimination of lactic acid by the muscle. The consequence is the accumulation of lactic acid and consequently of $\mathrm{H}+($ in fact of $\mathrm{H} 3 \mathrm{O}+$ ). Although the abandonment of an exercise of the aforementioned characteristics is multifactorial, when the activity of glycolysis is very high, the organism enters in a situation of acute metabolic acidosis, partially compensated with respiratory alkalosis. That is, it has ended with a situation of acid-base imbalance as indicated in table 1. 
Role of the kidney during exercise and recovery: Renal function during exercise of increasing intensity and limited duration is double. On the one hand, the renal circulation is one of the circulatory zones where there is a restriction of the blood flow, allowing a derivation of the renal flow towards the active territories. On the other hand, it intervenes in the recovery of the triggered metabolic acidosis state (see above). Next, the current knowledge of these two functions is reviewed, with more information on the role of the kidney during exercise than in recovery

Repercussion of renal flow bypass. Several authors [6,7], argue that during exercise there is a decrease in renal blood flow (RBF), renal plasma flow (RPF), glomerular filtration rate (GFR) and filtration fraction (FF). This reduction is an "intelligent" response to the mechanisms of cardiac output regulation. Indeed, not only with the increase in cardiac output is sufficient to supply the muscles during the exercise of increasing intensity. Redistribution of the largest volume of blood expelled in one minute is necessary. Considering that resting FSR is $20 \%$ of cardiac output ( $6 \mathrm{~L} / \mathrm{min}$ ) $=1200 \mathrm{ml} / \mathrm{min}$ ), different authors have found decreases in FSR that vary considerably (15 to 60\%). This is due to the study techniques, characteristics of the exercise and animal species studied. However, a reduction of $3 \%$ in cardiac output in maximal exercise $(25 \mathrm{~L} / \mathrm{min})=750 \mathrm{ml} / \mathrm{min})$, would imply a reduction of $40 \%$ in relation to resting values. The reduction of FSR during intense physical exercise suggests that nephrons may be "damaged".

The reduction of the FSR naturally implies a decrease in the RPF. However, the important thing and what has awakened the curiosity of the researchers is to know whether, despite this reduction, the glomerular filtration (FG) value is maintained. If this were to happen, it would necessarily imply an increase in the filtration fraction (FG / FPR). Again, the results are controversial, as some researchers have not observed variation in the FG, while others have recorded declines even of 50\%. Therefore, the FF can be increased or maintained at the same value as at rest. In any case, how does the kidney regulate $\mathrm{FG}$ during exercise?

Mechanisms that could explain the variations of the FPR, FG and FF. Two mechanisms have been proposed to explain the response of the FG during the exercise Fallo F (1993), Johansson BL et al. 1987, McKelvie RS et al. 1989, Poortmans JR 1977: $[6,10,17,18]$ Self-regulation and nervous regulation. The net effect of the mechanism of self-regulation would be a vasoconstriction of the efferent arteriole, which would make it possible to keep the GFR relatively constant despite the vasoconstriction of the afferent arteriole. Since the blood is "stagnant" in the glomerulus, glomerular patency would increase, favoring glomerular filtration. However, this may also be the reason for the appearance of pathological renal manifestations, such as the appearance of proteins, blood cells or both in urine, which is relatively frequent in background athletes. On the other hand, the action of the sympathetic vegetative nervous system, which causes a generalized vasoconstriction, would allow the derivation of the blood flow to the active territories and the modulation of the mechanism of self-regulation. Based on these two mechanisms, it is postulated that the combined effect of both is the maintenance of the filtration pressure and consequently of the glomerular filtration.

Intervention of renal function in restoring the acid-base balance. From a performance point of view, the post-exercise recovery process is essential to be able to "assimilate" training loads. However, documentation is scarce $[9,19]$. Therefore, the role of the kidney after intense exercise with a high production of lactic acid is here subjected to a more theoretical analysis than the result of contracted research.

After an exercise of the aforementioned characteristics, a state of metabolic acidosis has occurred (Table 1 and Figure 1). This imbalance of the acid-base state has an important renal compensation. The tubular function will increase to the purpose of: 1) reabsorb filtered bicarbonate ( $18 \mathrm{mM} / \mathrm{L}$ in table 2 ) formation of spent bicarbonate (go from $18 \mathrm{mM} / \mathrm{L}$ to $24 \mathrm{mM} / \mathrm{L}$ ) and eliminate the acid produced by the urine. In a simple way these two functions are exposed and the reader is referred to the texts of human physiology for more information. 


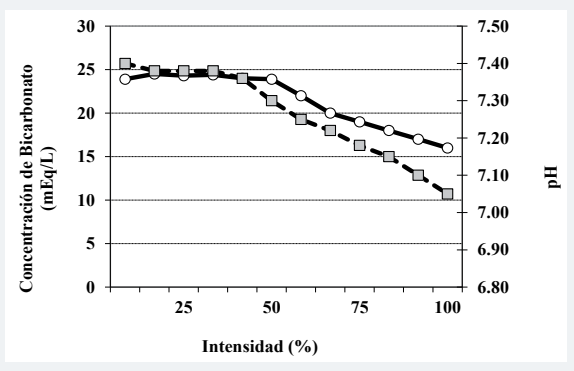

Figure 1: Resorption of filtered bicarbonate.

Resorption of filtered bicarbonate. At rest, this is a complex phenomenon in which most of the bicarbonate of the filtered bicarbonate is reabsorbed in the first part of the nephron (80\%) and the rest in the last part of the nephron (20\%). It seems coherent to think that after exercise the activity of the nephron is equivalent to the rest situation, so that the $18 \mathrm{mM}$ / L that have remained as a consequence of the buffering of the lactic acid are completely reabsorbed. Naturally, it is unknown whether the proportions of reabsorption of the bicarbonate in the different parts of the nephron are maintained.

Formation of spent bicarbonate. With the reabsorption of the filtered bicarbonate becoming important, the formation of "new bicarbonate" (6 mM / L) is of paramount importance. Although the kidney is capable of forming new bicarbonate by means of two buffer systems, dibasic phosphate / monobasic phosphate (HPO42- / H2PO4-) and ammonia / ammonium ion ( $\mathrm{NH} 3 / \mathrm{NH} 4+$ ), the latter is the most important, since it is responsible for forming the $60 \%$ "new bicarbonate". In an elementary way, the tubular cells have a high metabolic activity with glutamic acid, so that they release ammonium ion and keto-glutarate. The ammonium ion is released into the tubular fluid and consequently into the urine. Thus, $60 \%$ of the acid load, which would be released in the form of $\mathrm{H}+$ through the urine ( $\mathrm{pH}$ urine), is released in the form of ammonium ion, avoiding a very high acid load in urine. The amount of acid that is not buffered by one of the two systems (HPO42- / H2PO4- or NH3 / NH4 +) are released as free protons and are measured through the $\mathrm{pH}$ of the urine

Therefore, taking as an example the data shown in table 1, the tubular function:

$1^{\circ}$ ) reabsorbs the $18 \mathrm{mM} / \mathrm{L}$ that have remained after the buffering of the lactic acid produced during the exercise

$2^{\text {nd }}$ ) formation of $6 \mathrm{mM} / \mathrm{L}$ in order to restore the normal concentration of bicarbonate $(24 \mathrm{mM} / \mathrm{l})$. As a result, a greater amount of titratable acidity ( $\mathrm{NH} 4+$ and $\mathrm{H} 2 \mathrm{PO} 4-$-) and free protons in urine is eliminated by urine, that is, the $\mathrm{pH}$ of the urine decreases. The $\mathrm{pH}$ of the urine can decrease from 1 to 2 units with respect to the resting values (around 6.0).

The renal function during the exercise of constant intensity and prolonged duration

Unlike exercise of increasing intensity and limited duration, during an exercise of relatively constant intensity and prolonged duration, the kidney participates in hydroelectrolytic conservation. Using logical reasoning it is feasible to think that kidney function has the purpose of counteracting the losses that are produced by other ways of eliminating the heat generated during this type of exercise. The most important form of heat removal in homothermal animals is sweating or equivalent forms of water loss by evaporation. As shown in table 2, the loss of water through sweating can reach $70 \%$ of the losses. Thus, during an exercise such as the ultra-marathon can produce oliguria (15 to 50\%), although there may even be an increase in diuresis, due to multiple causes such as intensity, previous hydration, temperature, etc. Next, the role of renal function in this type of exercise is briefly discussed.

Unlike the role of the kidney during recovery, information regarding hydration and 
prolonged exercise is very abundant and, indirectly, renal function is deduced during this type of exercise. Thus, for example, doing an elementary search with the following terms "hydration AND exercise" in PubMed shows 1106 records and adding to the indicated search the term "renal function" the search is reduced to 53 records, when the search terms are found anywhere in the text. Therefore, then, I will rely not so much on the existing literature, but on common sense on the basis of physiology.

Functional sense of the tubular function for hydroelectrolytic control: The urine, in addition to decreasing its volume, would increase its osmolarity, when the mechanism of ADH-thirst is set in motion. However, the osmolarity of the urine during a physical effort can vary due to, among other reasons, to the state of previous hydration, to the rehydration during the same and to the environmental conditions (humidity and temperature). It has been found that the concentration of ADH in plasma increases at a certain intensity of effort, facilitating the reabsorption of water and salt. This seems an obvious effect, since, although the sweat is hypotonic with respect to the plasma, the "sodium loss" through the skin should not increase through the kidney. The stimulus for ADH secretion may be the result of a variation in osmolarity, total blood volume, or both. The increase in salt reabsorption contributes to the increase in aldosterone secretion and has a response similar to that of ADH. The mechanism by which aldosterone secretion is stimulated during physical exercise is not sufficiently clarified and could intervene: concentrations of other hormones, renin levels and potassium concentration in plasma.

However, a simple calculation determines that the oliguria does not have a purpose of water replacement. If we consider a reduction in urine volume of $1.5 \mathrm{ml} / \mathrm{min}$ by half $(0.75 \mathrm{ml} / \mathrm{min})$, it seems to be an important water saving. Now, if we value the clearance of free water, the question is not so clear. Under normal conditions this value is frequently negative. In this way, oliguria does not represent a great saving of water. For this reason, several authors $[10,11,17,20-24]$, have proposed that more than in a quantitative sense, oliguria represents a qualitative "saving", to be able to intervene in the cooling of the skin, evaporation and maintaining the flow to the muscles.

Figure 2 shows the results of a study [25] concerning osmolar clearance and free water in two circumstances: with or without water intake. The values of osmolar clearance and free water before and after exercise have a very similar behavior, which suggests that voluntary ingestion does not seem to be effective in reducing the decrease in the ability to concentrate urine under the indicated experimental conditions.

Mechanism of regulation: Stress oliguria necessarily suggests an increase in the reabsorption of water and osmotically active electrolytes [6,17,23,24,26-28]. An increase in sodium reabsorption has been indicated. The increase in sympathetic activity, the increase in FF, the increase in the concentration of hormones whose target organ is the kidney (natriuretic factor, angiotensin, aldosterone and ADH) could intervene in the increase of salt reabsorption and, therefore, in the decrease in its elimination by urine. Studies in animals seem to indicate that, during exercise, sympathetic activity is the main determinant of the increase in salt reabsorption. The renin-angiotensin-aldosterone system increases its activity during exercise with direct effects of some of the components of the system on tubular salt reabsorption.

Practical applications: Given the information that the athletes have, alterations in the hydroelectrolytic state have also been recorded [11], such as: 1) positive free water clearance. This implies that a greater amount of water is eliminated than solutes, 2) hyponatremia. This alarming state is due to an exaggerated loss of sodium by sweating, accompanied or not by a difficulty in eliminating hypotonic urine and 3) difficulty in rehydration. These alterations are caused by renal impairment (decreased tubular sensitivity to hormones) or extra renal causes difficult to elucidate.

Another interesting aspect, related to the homeostasis of body fluids, is to know what type of drink is the most appropriate to ingest. A priori, to know the composition 


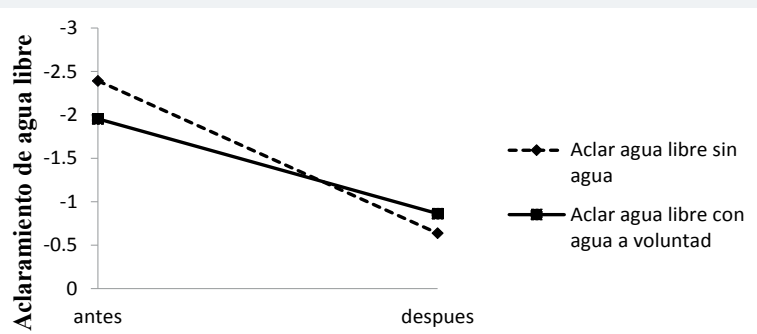

Momento de la determinación

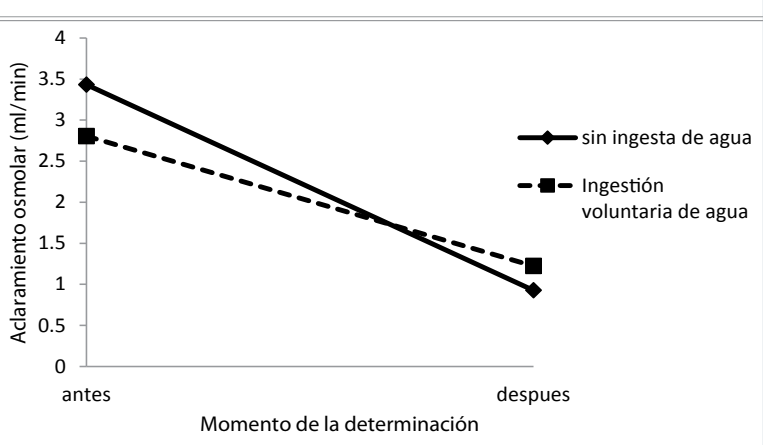

Figure 2: Moment of determination

of the liquid necessary to balance the losses, it would be enough to know precisely the content of the sweat losses. In an unpublished study, commercial beverages with different mineral waters were compared, in relation to: mineral concentration, carbohydrate content and price. An important conclusion of the mentioned work, was that according to the indicated characteristics, the replacement was more economical and equally effective, by ingesting mineral water with a slight preparation. It follows, then, that any mineral water offers the same advantages as all the products that are currently marketed. Moreover, certain mineral waters offer other advantages from the point of view of health, which do not have those marketed.

\section{References}

1. Kenney WL, Wilmore J, Costill D. Physiology of sport and exercise 6th edition. Human kinetics. 2015; 648. Ref.: https://goo.gl/fUKyPp

2. McArdle WD, Katch Fl, Katch VL. Exercise physiology: nutrition, energy, and human performance. Lippincott Williams \& Wilkins. 2010; Ref.: https://goo.gl/Yrcw8P

3. Berg U, Bohlin AB, Freyschuss $U$, Johansson BL, Lefvert AK. Renal function and albumin excretion during exercise in children during remission of the minimal change nephrotic syndrome. Acta Paediatr Scand. 1988; 77: 287-293. Ref.: https://goo.gl/AMytPM

4. Castenfors J. Renal function during exercise with special reference to exercise proteinuria and the release or renin. Acta Physiol Scand Suppl. 1967; 293: 1-44. Ref.: https://goo.gl/QXmVid

5. Irving RA, Noakes TD, Burger SC, Myburgh $\mathrm{KH}$, Querido D, et al. Plasma volume and renal function during and after ultramarathon running. Med Sci Sports Exerc. 1990; 22: 581-587. Ref.: https://goo.gl/bJycVs

6. Poortmans JR. Exercise and renal function. Exerc Sport Sci Rev. 1984; 1: 125-153. Ref.: https://goo.gl/iNRuip

7. Castenfors J. Renal function during prolonged exercise. Ann N Y Acad Sci. 1977; 301: 151-159. Ref.: https://goo.gl/Xy2qER

8. Irving RA, Noakes TD, Buck R, van Zyl Smit R, Raine E, et al. Evaluation of renal function and fluid homeostasis during recovery from exercise-induced hyponatremia. J Appl Physiol. 1991; 70: 342348. Ref.: https://goo.gl/n2AXpo

9. Irving RA, Noakes TD, Raine RI, Van Zyl Smit R. Transient oliguria with renal tubular dysfunction after a 90 km running race. Med Sci Sports Exerc. 1990; 22: 756-761. Ref.: https://goo.gl/j41VmD

10. Johansson BL, Berg $U$, Bohlin AB, Lefvert AK, Freyschuss U. Exercise-induced changes in renal 
function and their relation to plasma noradrenaline in insulin-dependent diabetic children and adolescents. Clin Sci (Lond). 72: 611-620. Ref.: https://goo.gl/RQdqp5

11. Zambraski EJ. Renal regulation of fluid homeostasis during exercise. In: In Gisolfi CV, Lamb DR. (eds.) Fluid homeostasis during exercise Carmel Indiana Benchmark Press c1990; 247-280.

12. Neumayr G, Pfister R, Hoertnagl H, Mitterbauer G, Getzner W, et al. The effect of marathon cycling on renal function. Int J Sports Med. 2003; 24: 131-137. Ref.: https://goo.gl/CjH78K

13. Neumayr G, Pfister R, Hoertnagl H, Mitterbauer G, Prokop W, et al. Renal function and plasma volume following ultramarathon cycling. International journal of sports medicine. 2005; 26: 2-8. Ref.: https://goo.gl/jzwukm

14. Silberberg MS. Chemistry, the molecular nature of matter and change, 3rd ed., McGraw-Hill, Boston, Mass., USA. 2003; 777. Ref.: https://goo.gl/VK1wDD

15. Johnson RL, Heigenhauser GJ, Hsia CC, Jones NL, Wagner PD. Determinants of gas exchange and acid-base balance during exercise. Handbook of Physiology. Exercise: Regulation and integration of multiple systems. 1996; 515-584. Ref.: https://goo.gl/VaL6v1

16. Halestrap AP. The monocarboxylate transporter family-structure and functional characterization. IUBMB life. 2002; 64: 1-9. Ref.: https://goo.gl/9rxbDj

17. Fallo F. Renin-angiotensin-aldosterone system and physical exercise. J Sports Med Phys Fitness. 1993; 33: 306-312. Ref.: https://goo.gl/AN31WA

18. McKelvie RS, Lindinger MI, Heigenhauser GJ, Sutton JR, Jones NL. Renal responses to exerciseinduced lactic acidosis. Am J Physiol. 1989; 257: R102-108. Ref.: https://goo.gl/pHvaQ2

19. Ishikawa I. [Post-exercise acute kidney failure]. Nippon Naika Gakkai Zasshi. 2005; 94: 1949-1955.

20. Dann EJ, Gillis S, Burstein R. Effect of fluid intake on renal function during exercise in the cold. Eur $J$ Appl Physiol Occup Physiol. 1990; 61: 133-137. Ref.: https://goo.gl/iPtE2Y

21. De Moraes R, Gioseffi G, Nóbrega AC, Tibiriçá E. Effects of exercise training on the vascular reactivity of the whole kidney circulation in rabbits. J Appl Physiol. 2004; 97: 683-688. Ref.: https://goo.gl/ft7ZrZ

22. Fuller $\mathrm{JH}$, Bernauer EM, Adams WC. Renal function, water and electrolyte exchange during bed rest with daily exercise. Aerosp Med. 1970; 41: 60-72. Ref.: https://goo.gl/SkaMh8

23. Grignolo A, Koepke JP, Obrist P. Renal function, heart rate, and blood pressure during exercise and avoidance in dogs. Am J Physiol. 1982; 242: R482-490. Ref.: https://goo.gl/jJa4TW

24. McKeever KH. Effect of exercise on fluid balance and renal function in horses. Vet Clin North Am Equine Pract. 1998; 14: 23-44. Ref.: https://goo.gl/FYpHjg

25. Otani $H$, Kaya $M$, Tsujita J. Effect of the volume of fluid ingested on urine concentrating ability during prolonged heavy exercise in a hot environment. J Sports Sci Med. 2013; 12: 197-204. Ref.: https://goo.gl/YZzGrN

26. Castenfors $\mathrm{J}$. Renal function during exercise. With special reference to exercise proteinuria and the release of renin. Acta Physiol Scand Suppl. 1967; 293: 1-44. Ref.: https://goo.gl/qV3bP3

27. Freund BJ, Wade CE, Claybaugh JR. Effects of exercise on atrial natriuretic factor. Release mechanisms and implications for fluid homeostasis. Sports Med. 1988; 6: 364-377. Ref.: https://goo.gl/EmntEj

28. Lichtig C, Levy J, Gershon D, Reznick AZ. Effect of exercise on the kidney of aging mice. Isr J Med Sci. 1989; 25: 376-381. Ref.: https://goo.gl/WvuTN5

29. Hiraki K, Kamijo-Ikemori A, Yasuda T, Hotta C, Izawa KP, et al. Moderate-intensity single exercise session does not induce renal damage. J Clin Lab Anal. 2013; 27: 177-180. Ref.: https://goo.gl/m1x5HQ

30. Poortmans JR, Vanderstraten J. Kidney function during exercise in healthy and diseased humans: An update. Sports med. 1994; 18: 419-437. Ref.: https://goo.gl/aQow5M

31. Grimby G. Renal clearances during prolonged supine exercise at different loads. J Appl Physiol 1965; 20: 1294. Ref.: https://goo.gl/24cTLh

32. Smith $\mathrm{JH}$, Robinson S, Pearcy M. Renal responses to exercise, heat, and dehydratation. J Appl Physiol. 1952; 4: 659. Ref.: https://goo.gl/qXKeqV 